\title{
REVIEWS
}

\section{Aging and work: the occupational health services' perspective}

\author{
Peter Westerholm, Åsa Kilbom
}

The issues of relations between aging and work ability have been subject to scientific debate for many years. Mostly the discussion stems from two opposed extremes of opinion, laying emphasis on the biological process of declining function with age, and the accumulation with time and age of knowledge and experience. The process of biological decline affects and imposes constraints on functions and performance which are predominantly dependent on physical strength and endurance, characteristics which are seen as inversely related to age. ${ }^{1}$ This notion is to be contrasted with the well known relation between age and enhanced usefulness and capacity due to experience accumulated over a long lifespan. Thus, according to observations in studies of developmental psychology during aging people conserve their capacities and develop them further in response to new tasks. This results in added value of qualified expert functions and management skills. ${ }^{2}$

Clearly, both biologically determined functional decline and age determined accumulation of knowledge and experience need to be examined in assessing relations of age to work ability and performance. This dualism of concepts has been described and discussed-for example, by Minois and Laville. ${ }^{34}$ Smith has also described the contributions of such determinant factors on age in occupations. ${ }^{5}$

\section{Functional capacity and age}

Most published studies have focused on the aspect of biological aging, this phenomenon seemingly being programmed and observable in many aspects. The biological decline process starts early in life, in some aspects even soon after adolescence. It is important, however, to be aware that such age dependent changes in biological functions have mostly been studied experimentally in situations in which the studied groups have been subjected to physiological strain during short periods. The studies have, moreover, seldom been carried out under conditions bearing resemblance to realistic workplaces and demands. Nevertheless, the studies which have been carried out support the notion that age is an important factor to consider when it comes to assessing the goodness of fit between work tasks and demands on the one hand and work capacity of those employed to do the task on the other. ${ }^{6}$ This applies in particular to work strain on the musculoskeletal or cardiovascular systems and shiftwork that disturbs circadian rhythm.

It is important to note that when cognitive functions and age have been considered the studies have focused mainly on simple functions in experimental study designs, and population studies have rarely been fully controlled in their design and selection of study populations. Moreover, few studies have been longitudinal.

In studies considering cognitive functions and age a common finding has been the large differences between and within people. These have been of the same order of magnitude as the variations found in decline of biological functions, as observed by Rabbitt. ${ }^{7}$ There seems, nevertheless, to be a downward trend in many cognitive functions with age which is difficult to explain away by the impact of other factors independent of age. An extensive review and analysis of these issues has been published by Salthouse.

In studies of work performance reviews have been written by-for example, Davies et al and Rhodes. ${ }^{9}{ }^{10}$ Rhodes reviewed the results of 30 studies and found notable inconsistencies in relations between age and performance. Some studies indicated enhanced performance with advancing age; others indicated a decline.

It is a well known fact that there exist, in general and in business, many myths and unfounded preconceived opinions on the work performance and capacities of elderly workers. There are widely disseminated stereotyped opinions on work capacity, coping capacities, resistance to adaptation, declining creativity, decreased productivity, and poor suitability in economic decision making. Davies et al have published a modern review of these attitudes and stereotypes. ${ }^{9}$

The shortcomings of the methodology used have, during the past decade, inspired development of new ideas and solutions to problems taking into account the actual performance of older workers in realistic work tasks. In such studies the subjects should be given full freedom to use their coping skills and experience in offsetting the impact on age dependent biological functions for carrying out work tasks. ${ }^{11}$ Obviously, the impact of chronic 
disease or selection into or out of jobs can be expected to have profound effects on observed performance, regardless of whether or not functioning or performance is tested for realistic work tasks and whether or not the experimental testing conditions are relevant. Longitudinal studies, including the interaction between work conditions and age, are needed to resolve this issue.

In considering the large variations between people in cognitive and physical capacities and work performance already mentioned, Warr has recommended that flexible and nonconventional work arrangements should be practiced, to optimise the skills and experience characteristic of many aging employees. ${ }^{12}$

\section{Occupational health services for an aging workforce}

As a consequence of the aging of the workforce, occupational health services must consider whether their strategies for pre-employment health examinations and health surveillance should be revised. They must consider the issues of health surveys specifically directed towards certain age groups, and consider whether age limits are an appropriate approach to high risk jobs. The methods of collaboration with personnel departments, management, and the employees themselves may have to be modified. Personnel departments need information and advice for recruitment of elderly job seekers, and management, from department heads to supervisors, need recommendations on suitable job designs for aging employees. Employees need information and advice to assist them in choosing a career that considers the possible development of chronic diseases and functional impairments. Because of the many myths and prejudices about aging people, the occupational health professional needs to spend more efforts on information and should take a more proactive role in job placement and job design.

\section{Health surveys and pre-employment medical examinations}

This new role of the occupational health professional is not limited to considering only occupational and work related illnesses. In a recent investigation in the Nordic countries ${ }^{13}$ the aetiological fraction of work related illness was assessed in nine main categories of illness. These fractions varied from about $4 \%$ for cancer to about $45 \%$ for skin diseases, with a mean of about $10 \%-15 \%$. Despite the large uncertainties of such assessments, it is obvious that occupational health services must not only consider the impact of work related diseases. With increasing age, both physical and mental capacities undergo changes, and the panorama of illnesses partly differs from those of young and middle aged people. These changes may have implications for the ability to perform work and for the medical support needed.

Cardiovascular disease and psychological and musculoskeletal disorders are the most common illnesses in working populations. Doubtlessly they display increased prevalence and incidence in the aging workforce. When considering pre-employment medical examinations and general health surveys the question is whether available medical screening methods have enough sensitivity and specificity to identify illnesses, and if the predictive power is sufficient to warrant special health screening in the aging workforce. In general, the trend over the past decades has been to advise against general health screening, because of its high costs and poor performance in terms of sensitivity and specificity. It has been considered more cost efficient to direct screening towards certain high risk groups, and in the case of the aging workforce legal requirements for health surveillance are implemented in many countries. Common examples are health checks and functional testing of fire fighters, drivers, and pilots. There is, however, a notable lack of scientific evaluations of such targeted health screening programmes. Conway and Hathaway have recently reviewed current issues on effectiveness and cost efficiency aspects of occupational medical surveillance programmes. ${ }^{14} 15$

In a study by de Kort et al from The Netherlands, the validity of pre-employment medical examinations were tested in more than 100000 job applicants. ${ }^{16}$ Although about $20 \%$ of the applicants had a medical diagnosis, only $0.6 \%$ were rejected, although the rejection rate increased with age. It was only for musculoskeletal diagnoses that rejections were related to the actual job demands.

In conclusion, general health surveys of elderly employees should not be encouraged. Whenever an occupational health service is in charge of employees with special physical or cognitive demands, issues to consider are whether health surveys aimed at such groups are warranted, how they should be designed, and whether they should be undertaken more often for elderly employees. Obviously, medical screening procedures also raise ethical issues which will not be elaborated here.

\section{Job placement and job design}

The physical capacities that need consideration for job placement and job design encompass the sensory organs and the physical working capacity. To compensate for the gradual, age related deterioration in vision the lighting needs to be increased by a factor of two to three up to the age of 60 , and correction for age related presbyopia is usually needed from the age of 40 . Poor lighting adds to the total stress level of individual people, and insufficient compensation for hyperopia reduces the working capacity-for example, in work at a visual display terminal. This knowledge, although available for a long time, is often unknown in the workplace. The remedies are simple, not costly, and need to be conveyed to the workplace by the occupational health professionals. Noise induced hearing loss is common among elderly male employees in many jobs. Apart from the obvious role of the occupational health professional in prevention, there is a need for information at the workplace about the consequences of hearing loss for the 
understanding of verbal instructions and warning signals.

It is a common misunderstanding that physically heavy jobs are so unusual nowadays that no special provisions need to be made to adjust workloads. It is true that traditionally heavy jobs in transport, mining, and forestry are now less common due to rationalisation, but many manufacturing and construction jobs are still physically demanding. Although work demands are not heavy in the traditional sense, many female occupations induce work loads that are high in relation to the capacity of elderly women. According to Ilmarinen et al, $19 \%-26 \%$ of municipal employees aged $48-62$ years in Finland reported physical or psychological symptoms of potentially harmful stress at work. ${ }^{6}$ About $8 \%$ of women and $17 \%$ of men over 50 in Sweden perform physically heavy work (heavy manual handling and work that induces hyperventilation) for more than $25 \%$ of their working hours. However, among younger age groups such symptoms are just as prevalent, and therefore the findings do not support special actions for the aging workforce. The results rather emphasise the need to optimise physical workloads and to inform management about suitable work designs for all age groups, preferably by using the ergonomics expertise within the occupational health service.

The cognitive work tasks that need attention when placing elderly employees seem to be those in which rapid learning and fast reactions to unexpected events are needed. ${ }^{812}$ However, when learning new skills without time stress, and when responding to sudden events that are familiar, no differences between young and elderly people have been found. In some situations the aging workforce may even be better, especially in response to complex tasks and when making decisions with no available pre-existing rules.

It has been suggested that the rate of recovery-whether from physical or mental exertion-is slower among aging people. Physical and mental stress reactions may therefore ensue if the pace of work cannot be individually adjusted, so the aging workforce would be particularly affected by external pacing of work. However, recommendations on flexible work systems and self selection of pace are general concepts of favourable work designs, and are likely to favour young and middle aged employees to almost the same degree.

\section{Development trends in working life}

In contemplating the relations of age and work demands it is necessary to consider the implications of technological change and development of the work organisation. These changes are being introduced and implemented at differing rates in industry and increasingly so in the service sector of the labour markets. In general, the technical transformation implies decreasing physical strain and increasing demands on cognitive functions and social skills in management of interpersonal relations. At the same time an increased level of education and training is found in the whole population. The labour market shows trends to polarisation. This means that segments of qualified and competent workers who are in demand are attracted to employment where work is carried out under good hygienic and ergonomic standards. Other work has less attraction for employees who often have to cope with working conditions of poor hygienic and ergonomic standards.

Studies of how the age factor contributes to changes in functions and capacities at work cannot be properly carried out if the transformation of work and working conditions over time is disregarded.

\section{Conclusions}

(1) The difficulties in characterising productivity, skills, and occupational health of aging workers have been recognised for a long time and remain to be resolved.

(2) An important factor when considering the relation between work performance and age is the considerable variation between people in physiological, cognitive, and social functioning, which increases over the human lifespan. This calls for an individual approach when seeking to optimise goodness of fit between individual characteristics and work tasks.

(3) Attempts to differentiate between aging workers and other workers, and setting up separate occupational health standards for such distinctions, are not to be encouraged as they are, at the present time, not evidence based.

(4) There is no scientific basis for launching health screening programmes focusing on older staff members. Such programmes are in general difficult to justify in terms of cost and efficiency. When high physical or cognitive work demands exist, adequately designed health surveys or functional tests may be appropriate.

(5) Age related decline of biological and physiological functions may affect work performance only when work performance is primarily dependent on such functions-for example, muscular strength and endurance.

(6) The occupational health practitioner should pay special attention to job placement of aging employees. Jobs with heavy physical demands or high demands on speedy responses to unexpected situations should probably be avoided or compensated for with technical measures.

(7) Middle aged and old people learn and develop during their whole lives.

(8) There is a great need of, but little demand for, information on the state of evidence-based knowledge on aging and work performance. These needs exist and should be considered at the highest levels of society and at business and workplace levels. The target groups in business are people with responsibilities at the top level, middle management, and management on the shopfloor. The trade unions contain, in their different levels of organisation, many target groups. It is evidently the responsibility of occupational health 
professionals to generate this correct and pedagogically well suited information and disseminate it.

(9) The need to individualise to achieve an optimal fit between personal characteristics and skills on one hand and the work tasks on the other poses ethical challenges to the health professionals involved. It is important that this does not lead to marginalisation or rejection of people with functional deficiencies or health defects. The basic orientation must always be to improve workplace conditions for all age groups.

1 de Zwart B, Frings-Dresen M, van Dijk F. Physical workload and the ageing worker: a review of the literature. Int Arch accup Environ Health 1995;68:1-12.

2 Baltes P. Theoretical propositions of life-span developmental psychology: on the dynamics between growth tal psychology: on the dynamics between grow
decline. Developmental Psychology 1987;23:611-26.

3 Minois G. Histoire de la vieillesse-de IAntiquité à la Renaissance. Paris: Fayard, 1987.

4 Laville A. Travail et ages, del la recherche à laction. In: Marquie J, Paumes D, Volkoff S, ed. Le Travail au fil de l'age. Toulouse: Collection Travail, 1995.
5 Smith J. Age and occupation: the determinants of male occupational age structures. Hypothesis $\mathrm{H}$ and hypothesis A. $\mathcal{F}$ Gerontol A Biol Sci Med Sci 1973;28:484-90.

6 Ilmarinen J. The aging worker. Scand $\mathcal{F}$ Work Environ Health 1991;17(suppl 1):1-141.

7 Rabbitt P. Management of the working population. Ergonomics 1991;34:775-90.

8 Salthouse T. Theoretical perspectives on cognitive aging. Hillsdale, NY: Erlbaum, 1991

9 Davies D, Matthews G, Wong C. Aging and work. In Cooper C, Robertson I, eds. International review of industrial and organizational psychology. Chichester: Wiley, 1991:149 211.

10 Rhodes S. Age-related differences in work-attitudes and behaviour. Psychol Bull 1983;93:328-69.

11 Salthouse TA. Influence of experience on age differences in cognitive functioning. Hum Factors 1990;32:551-69.

12 Warr P. Age and employment. In: Dunette M, Hough L, ed Handbook of industrial and organisational psychology. Palo Alto: Consulting Psychologists Press, 1992:485-550.

13 Hansen S. Arbejdsmilio og samfundsøkonomi. In: Nordisk Ministerråd Nordic Council of Ministers) Nord 1993:22.

14 Conway H, Simmons J, Talbert T. Effects of occupationa medical surveillance programs as perceived by respondents to the Occupational Health and Safety Administration. Occup Med 1993;35:687-97.
Oc

15 Hathaway J. Medical surveillance-extent and effectiveness. f Occup Med 1993;35:698-700.

16 de Kort W, Fransman L, van Dijk F. Pre-employment medical examinations in a large occupational health service. Scand $\mathcal{F}$ Work Environ Health 1991;17:392-7.

\section{Vancouver style}

All manuscripts submitted to Occup Environ Med should conform to the uniform requirements for manuscripts submitted to biomedical journals (known as the Vancouver style.)

Occup Environ Med, together with many other international biomedical journals, has agreed to accept articles prepared in accordance with the Vancouver style. The style (described in full in the $¥ A M A[1]$ ) is intended to standardise requirements for authors, and is the same as in this issue.

References should be numbered consecutively in the order in which they are first mentioned in the text by Arabic numerals on the line in square brackets on each occasion the reference is cited (Manson[1] confirmed other reports[2][3][4][5]). In future references to papers submitted to Occup Environ Med should include: the names of all authors if there are seven or less or, if there are more, the first six followed by $e t$ al; the title of journal articles or book chapters; the titles of journals abbreviated according to the style of Index Medicus; and the first and final page numbers of the article or chapter. Titles not in Index Medicus should be given in full.

Examples of common forms of references are:

1 International Committee of Medical Journal Editors. Uniform requirements for manuscripts submitted to biomed journals. ҰAMA 1993;269:2282-6.

2 Soter NA, Wasserman SI, Austen KF Cold urticaria release into the circulation of histmaine and eosinophil chemotactic factor of anaphylaxis during cold challenge. chemotactic factor of anaphylaxis

3 Weinstein L, Swartz MN. Pathogenic properties of invading micro-organisms. In: Sodeman WA Jr, Sodeman WA eds. Pathologic physiology, mechanisms of disease. Philadelphia: W B Saunders, 1974:457-72. 